\title{
Characterization of proteins by means of their buffer capacity, measured with an ISFET-based coulometric sensor-actuator system
}

\author{
W. Olthuis*, J. Luo \& P. Bergveld \\ MESA Research Institute, University of Twente, P.O. Box 217, 7500 AE Enschede, The Netherlands. \\ Tel: (0)53-892688. Fax: (0)53-328439.
}

\begin{abstract}
Proteins form the specific selector in many biochemical sensors. A change in one of the properties of such a protein has to be detected by an appropriate transducer, which completes the biochemical sensor. One of these properties is the buffer capacity of a protein. If the binding of a substance to a protein can significantly change the proton binding, which accounts for the buffer capacity of proteins, the detection of this changed buffer capacity enables the construction of a new type of biosensor.

It will be shown that the buffer capacity can be measured with an ISFETbased sensor-actuator device. The alternating generation of protons and hydroxyl ions by alternating current coulometry at a porous noble metal actuator electrode causes an associated small $\mathrm{pH}$ perturbation, which is detected by the underlying $\mathrm{pH}$-sensitive ISFET. The amplitude of the measured signal is a function of the buffer capacity of the solute, in which proteins can be present (or these proteins can be adsorbed in the porous actuator electrode of the device). A model describing the transfer function from the electrical input signal of the actuator to the resulting chemical output, which is subsequently detected by the ISFET pH sensor, is presented. Preliminary results of the measured buffer capacity of ribonuclease and lysozyme are presented.
\end{abstract}

Keywords: coulometry, ISFET, biosensor, buffer capacity.

\section{INTRODUCTION}

Proteins form the specific selector in many biochemical sensors. The application of proteins can generally be categorized into two groups

\footnotetext{
* Author to whom correspondence should be addressed.
}

according to the principle employed. One group of sensors employs the catalytic properties of proteins. The most successful and extensively studied proteins in this group are enzymes. The other group utilizes affinity reactions, of which the immunosensor based on the formation of an antibody/antigen complex is an example. A unique feature of using proteins as a part of the sensor is the high selectivity, either in a catalytic 
reaction or in a molecular binding (recognition). The sensors that incorporate catalytic proteins measure the concentration change in substrate or products rather than the proteins themselves. The sensors that use proteins as binding ligands mostly detect a change in some intrinsic property of the protein itself, such as charge density, molccular weight or refractive index. The transducer used in these cases can be an electrochemical one or an optical one. As has been pointed out before (Schasfoort et al., 1990), a practical problem which has to be solved in the construction of a biosensor is the effective transfer of the highly specific signal, either from an enzymatic reaction or from immunological binding, into a sensor-detectable one. pH ISFET-based enzyme sensors (ENFETs) (Van der Schoot and Bergveld, 1988) have actually employed proton-associated detection. However, this application is limited, since only a few enzymes, such as urease and glucose oxidase, can catalyze a reaction that gives rise to an associated $\mathrm{pH}$ change. An alternative, and possibly more effective, way is the determination of the change in the acid-base property of the protein itself. This determination, which has been investigated by titration (Tanford \& Epstein, 1954a, b; Tanford \& Wagner, 1954; Tanford et al., 1955; Nozaki \& Tanford, 1967; Nagasawa \& Holtzer, 1971; Roxby \& Tanford, 1971), can be achieved by coulometric sensor-actuator systems. It is possible to construct an ISFET-based affinity-type biosensor because the proton binding characteristics of a protein are related to the intrinsic properties of that protein. The research described in this paper will mainly be dedicated to the study of the proton dissociation and association behaviour of the analyte, including dissolved proteins, by means of an ISFET-based coulometric sensor-actuator system.

\section{Acid-base properties of proteins}

Proteins are macromolecules that are composed of one or more polypeptides linked by secondary bonds such as disulphide bonds, hydrogen bonds and covalent bonds, in a specific spatial conformation. This spatial conformation, referring to the secondary, tertiary and quaternary structure of proteins (Lehninger, 1975), is mainly determined by their primary structure (the primary structure of a protein refers to the sequence of the amino residues in the peptide chains). Most of the physical and chemical properties of a protein are similar to those of the long constituent polypeptides. However, proteins have some specific biological activities, such as enzymatic activity or specific immunological binding ability, originating from their spatial conformation.

A protein has many sites that are able to bind with or relcase protons. These sites are spatially distributed according to the conformation of the protein and are of importance in determination of the electrostatic interaction among the sites (Tanford, 1962). One of the methods of studying this interaction is by titration. Studies on proteins by hydrogen ion titration were inspired mainly by their simplicity, rapidity and the small quantity of sample needed (Haschemeyer \& Haschemeyer, 1973). Applications have dealt with the classification and counting of groups that can be titrated, as well as the stability and conformational change of the proteins upon binding with ions. In addition, studies have also been concerned with interactions between binding sites of different ions (especially metal cations) as well as some neutral molecules (Steinhardt \& Reynolds, 1969; Haschemeyer \& Haschemeyer, 1973). Such investigations provide the necessary insight for protein characterization by means of proton binding studies. The characterization of proteins by considering the interaction between the binding of protons and the binding of other species is of particular interest, and may lead to the development of new specific biosensors.

\section{Coulometry for acid-base titration}

Coulometry is an electrochemical analytical technique in which the quantity of the electrical charge used for generation of the titrant is a measure of the concentration of the electroactive reactant (Abresch \& Claassen, 1961). In classical coulometry a colour indicator or a separate electrode system is used for the detection of the end point. Measurement of the concentration change of the total volume of the sample during titration is carried out under equilibrium conditions and no diffusion is taken into account.

The material for a generating electrode has to be selected on the basis of the titrant to be generated. For the titration of an acid or base, a noble metal electrode is usually adopted. A constant current is often used in coulometric titration, and the quantity of charge is then calculated by the time of the electrolysis. The 
analyte can be either an acid or a base. If there are no other interfering redox couples, the titrant generated at the electrodes depends on the direction of the applied current:

Anode:

$$
2 \mathrm{H}_{2} \mathrm{O} \rightarrow 4 \mathrm{H}^{+}+4 \mathrm{e}+\mathrm{O}_{2}
$$

Cathode:

$$
2 \mathrm{H}_{2} \mathrm{O}+2 \mathrm{e} \rightarrow 2 \mathrm{OH}^{-}+\mathrm{H}_{2}
$$

The titration of an acid or base can be carried out by choosing a cathodic or anodic current, respectively.

\section{ISFET-based coulometric sensor-actuator systems}

Acid or base concentrations can also be determined by performing an acid-base titration with coulometrically generated $\mathrm{OH}^{-}$or $\mathrm{H}^{+}$ions at an actuator electrode in close proximity to a $\mathrm{pH}$ sensor. The titrant can be generated by the electrolysis of water at a noble metal actuator electrode, as previously mentioned (Olthuis et al., 1989, 1990). The $\mathrm{pH}$ sensor that is used as an indicator electrode to detect the end point in the titration curve consists of a $\mathrm{pH}$-sensitive ISFET. Figure 1 shows a schematic drawing of the device.

The time $t_{\text {end }}$, which is the time needed to reach the end point in the titration curve, is related to the acid or base concentration of the bulk solution via the process of free diffusion. The ISFET-based coulometric sensor-actuator device optimally uses the favourable properties of the $\mathrm{pH}$ sensor, i.e. its small, planar structure and especially its fast response.

Recently, a new ISFET-based coulometric sensor-actuator system was proposed employing

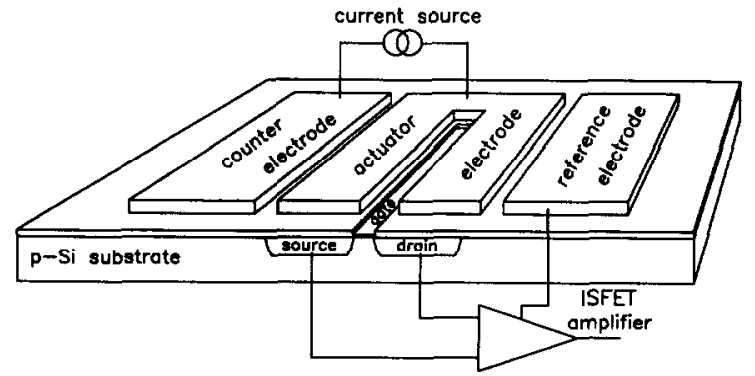

Fig. 1. Schematic representation of the basic elements of the ISFET-based coulometric sensor-actuator device with a flat actuator electrode. a porous noble metal, in this case porous gold, as an actuator closely shaped around and over the gate of the ISFET (Luo et al., 1993). The basic components of this system are shown in Fig. 2. Since the gate is fully surrounded by the porous actuator, the titration of the internal volume of the porous actuator will give rise to a smaller concentration gradient, which limits the diffusion of the species from the bulk solution to the gate of the ISFET. As a result, the amount of generated titrant needed for a coulometric titration is approximately linearly proportional to the concentration of the titrated species. Another advantage is that the system is less sensitive to convection. This makes the system more suitable for on-line applications. The other advantages, such as ease of operation and the possibility of constructing a dipstick device, still remain.

\section{Characterization of proteins by a sensor-actuator system}

Classical study of the proton dissociation or association equilibria of a protein requires precise titration. Either electrometric or spectrophotometric titrations are most frequently used, although some indirect methods also exist (Tanford, 1962). Among various kinds of electrometric titrations (Ashworth, 1964), potentiometry has predominated in earlier studies. None of the investigations we know of to date have been carried out by coulometry. We propose to use the coulometric sensor-actuator system for a protein study or characterization.

As has been mentioned above, a porous

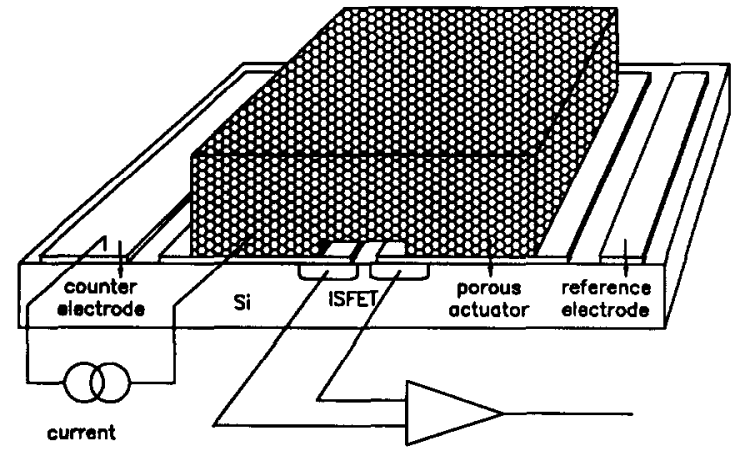

Fig. 2. Schematic representation of the basic components of the coulometric sensor-actuator system based on an ISFET with a gate-covering porous actuator electrode. 
actuator covering the gate forms a small reaction chamber which limits the diffusion of species to some degree. $\mathrm{pH}$ modulation can be achieved inside such a closed chamber by applying a small perturbation to the titrant, which can easily be generated coulometrically by applying an alternating current to the porous actuator. The associated $\mathrm{pH}$ change will be a function of the buffer capacity of the analyte and can be rapidly detected by the ISFET. This provides the unique possibility that the new coulometric sensor-actuator system will be able to determine the buffer capacity directly.

\section{PRINCIPLE OF OPERATION}

Buffer capacity is, by definition, the reciprocal of the slope of the titration curve. As well as the conventional way that uses complete titration, the buffer capacity can also be measured by applying a small perturbation to the titrant at different pHs. This is illustrated in Fig. 3. The solid curved line shown in this figure is the titration curve of an acid. The abscissa represents the equivalents of the added base (left from zero) and acid (right from zero) to the original species. If a small amount of titrant is added alternately, as shown in this figure, the resulting

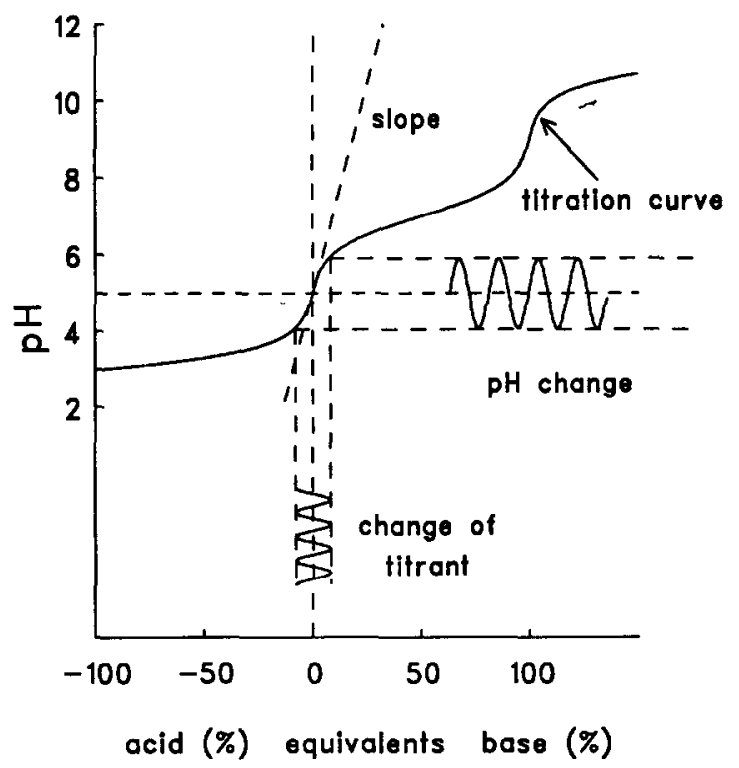

Fig. 3. Illustration of the buffer capacity measurement by means of an applied sinusoidal perturbation of the titrant.
pH changes will depend on the buffer capacity of the solution, i.e. the reciprocal of the slope of the titration curve at the $\mathrm{pH}$ concerned. Perturbation of the titrant can be generated coulometrically and the modulated $\mathrm{pH}$ can be detected by an ISFET. Both of these can be achieved by the ISFET-based coulometric sensor-actuator system with a gate-covering porous actuator. This operation of the system provides a dynamic way of measuring the buffer capacity. For reasons of simplicity, sinusoidal coulometry will be adopted, since it facilitates the mathematical treatment. The response of the system and determination of the buffer capacity will be dealt with in the next section.

\section{Mathematical description}

After the start of the coulometric generation of the titrant, the resulting diffusion is considered to be one-dimensional, which is reasonable because the geometric area of the actuator is much larger than its thickness. The concentration profiles of the species are divided into two parts, $C_{1}(x, t)$ and $C_{2}(x, t)$, representing the profiles of the species inside and outside the porous actuator, respectively. The variable $x$ represents the distance from the gate (at $x=0$ ) to the bulk, perpendicular to the ISFET, and $l$ is the thickness of the porous actuator. With other assumptions stated elsewhere (Luo et al., 1993), the derivation of the model can proceed.

First, a unit $\rho_{\mathrm{f}}$, defined as the titrant generated per unit time and per unit volume, will be introduced (Luo et al., 1993) to describe the titrant source.

For an applied sinusoidal current, generation of the titrant will exhibit a certain initial phase shift, $\theta$, because of the charge transfer and the mass transport from the actuator surface into the actuator pores. When this initial phase shift is taken into account, the applied sinusoidal current can be defined as

$$
i=I \cos (\omega t-\theta)
$$

where $I$ is the amplitude and $\omega$ is the angle frequency of the applied current. Then, the titrant production rate per unit volume, $\rho_{\mathrm{f}}$, as defined, is

$$
\rho_{\mathrm{f}}=\frac{I_{f} \cos [(\omega t-\theta)+\theta]}{F V_{\text {act }}}=\frac{I_{f} \cos \omega t}{F S l}
$$

where $I_{f}$ is the faradaic portion of the amplitude 
of the applied current $I, F$ is the Faraday constant, $V_{\text {act }}$ is the total volume of the porous actuator, and $S$ and $l$ are the geometric area and thickness of the porous actuator, respectively. Here the subscript $f$ is used to denote the corresponding faradaic quantity, because only the faradaic current takes part in the electrode reaction.

The equations governing the mass transport of the electroactive species inside and outside the porous actuator are expressed as (Luo et al., 1993)

$$
\begin{aligned}
\frac{\partial C_{1}(x, t)}{\partial t} & =D \frac{\partial^{2} C_{1}(x, t)}{\partial x^{2}}+\rho_{\mathrm{f}} \\
& =D \frac{\partial^{2} C_{1}(x, t)}{\partial x^{2}}+K \cos \omega t \quad 0<x<l \\
\frac{\partial C_{2}(x, t)}{\partial t} & =D \frac{\partial^{2} C_{2}(x, t)}{\partial x^{2}} \quad l<x<\infty
\end{aligned}
$$

where $D$ is the diffusion coefficient of the electroactive species, and $K=I_{f} / F S l$. The initial and boundary conditions are

$$
\begin{array}{ll}
t=0: & C_{1}(x, 0)=C_{2}(x, 0)=C_{0} \\
x=0: & \frac{\partial C_{1}(0, t)}{\partial x}=0 \\
x=l: & \frac{\partial C_{1}(l, t)}{\partial x}=\frac{\partial C_{2}(l, t)}{\partial x} \\
& C_{1}(l, t)=C_{2}(l, t) \\
x \rightarrow \infty: & C_{2}(x, t)=C_{0}
\end{array}
$$

where $C_{0}$ is the initial bulk concentration of the species.

Since the detection is carried out by the gate of the ISFET, which is located very close to the edge of the actuator $(x=0)$, only the solution of $C_{1}(0, t)$ is of interest. Because only the steadystate response is significant, the transient part of the general solution is disregarded. The steadystate response for $C_{1}(0, t)$ is

$$
C_{1}(0, t)=C_{0}+A \cos (\omega t+\varphi)
$$

where

$$
\begin{aligned}
& A=\frac{K}{\omega} . \\
& \sqrt{1-2 \exp \left(-\sqrt{\frac{\omega}{2 D}} 1\right) \cos \sqrt{\frac{\omega}{2 D}} 1+\exp \left(-2 \sqrt{\frac{\omega}{2 D}} 1\right)}
\end{aligned}
$$

$$
\varphi=-\frac{\pi}{2}+\tan ^{-1} \frac{\exp \left(-\sqrt{\frac{\omega}{2 D}} 1\right) \sin \left(\sqrt{\frac{\omega}{2 D}} 1\right)}{1-\exp \left(-\sqrt{\frac{\omega}{2 D}} 1\right) \cos \left(\sqrt{\frac{\omega}{2 D}} 1\right)}
$$

The response is sinusoidal, with the same frequency as the applied current. Its amplitude and phase shift are dependent on the frequency of the applied current, the diffusion coefficients of the active species, and the thickness of the porous actuator. It should be noted that the phase shift $\varphi$ of the concentration change given in eqn. (12) is defined with respect to the titrant production rate. If the phase shift is measured with respect to the applied current $i$, the initial phase shift $\theta$ has to be included, as indicated in eqn. (1).

\section{Buffer capacity dependent system response}

Considering a buffer system consisting of a weak acid ( $\left.\mathrm{HA} \Leftrightarrow \mathrm{H}^{+}+\mathrm{A}^{-}\right)$, the buffer capacity $\beta$, defined as the small amount of base $\mathrm{d}[B]$ needed to change the $\mathrm{pH}$ by $\mathrm{d} p H$, is given by (Perrin \& Dempsey, 1974)

$$
\beta=\frac{\mathrm{d}[B]}{\mathrm{d} p H}=2.3\left\{\frac{K_{\mathrm{a}} C_{0}\left[\mathrm{H}^{+}\right]}{\left(K_{\mathrm{a}}+\left[\mathrm{H}^{+}\right]\right)^{2}}+\left[\mathrm{H}^{+}\right]+\frac{K_{\mathrm{w}}}{\left[\mathrm{H}^{+}\right]}\right\}
$$

where $K_{\mathrm{w}}$ is the ionic product of water, $K_{\mathrm{a}}$ is the dissociation constant of the acid $\mathrm{HA}$, and $C_{0}$ is the initial bulk concentration of the acid, i.e. $[\mathrm{HA}]+\left[\mathrm{A}^{-}\right]$.

For the addition of a small amount of titrant $\Delta[B]$, the change in the bulk concentration is relatively small. Then, the corresponding $\mathrm{pH}$ change $\Delta p H$ is

$$
\begin{aligned}
\Delta p H & \cong \frac{\mathrm{d} p H}{\mathrm{~d}[B]} \Delta[B] \\
& =\frac{\Delta[B]}{2.3\left\{\frac{K_{\mathrm{a}} C_{0}\left[\mathrm{H}^{+}\right]}{\left.K_{\mathrm{a}}+\left[\mathrm{H}^{+}\right]\right)^{2}}+\left[\mathrm{H}^{+}\right]+\frac{K_{\mathrm{w}}}{\left[\mathrm{H}^{+}\right]}\right\}}
\end{aligned}
$$

If the adding of titrant is coulometrically generated at the porous actuator, the effective change of titrant $\Delta[B]$ should be taken as equivalent to the associated change in the concentration of the species that will be detected by the ISFET at $x=0$, i.e. $\Delta[B]=\Delta C_{1}(0, t)$ (see eqn. 10). The response to this $\mathrm{pH}$ change 
$\triangle p H$ at the gate of the ISFET is obtained by incorporating eqn. (10) into eqn. (14):

$$
\begin{aligned}
& \Delta p H(0, t)_{\mid \text {ISFET }} \cong \frac{\mathrm{d} p H}{\mathrm{~d}[B]} \Delta C_{1}(0, t) \\
& =\frac{A \cos (\omega t+\varphi)}{2.3\left\{\frac{K_{\mathrm{a}} C_{0}\left[\mathrm{H}^{+}\right]}{\left(K_{\mathrm{a}}+\left[\mathrm{H}^{+}\right]\right)^{2}}+\left[\mathrm{H}^{+}\right]+\frac{K_{\mathrm{w}}}{\left[\mathrm{H}^{+}\right]}\right\}}
\end{aligned}
$$

where $A$ and $\varphi$ are given by eqns. (11) and (12). The concentration $C_{1}(0, t)$ can be considered as constant and equal to the bulk concentration $C_{0}$ for a small titrant perturbation.

Equation (15) shows that the response of the ISFET with respect to a coulometrically generated titrant perturbation is inversely proportional to the buffer capacity of the analyte if the titrant perturbation is small. This indicates that the buffer capacity can be determined. It can be seen that this dynamic way of measuring differs from the conventional derivative titration in that the titrant is locally generated by coulometry, and the associated local $\mathrm{pH}$ changes are rapidly detected by the ISFET. The advantage is that the measurement can be carried out very rapidly without disturbing the bulk solution. However, it should be noted that the response is also a function of the frequency of the applied current and the geometric dimension of the actuator, as well as of the mobility of the species (see eqns. 11 and 12).

\section{EXPERIMENTAL}

\section{Sensor-actuator device with porous actuator electrode}

The procedure to make the coulometric sensor-actuator device has been described extensively elsewhere (Luo et al., 1991). A flat ISFET is used as the $\mathrm{pH}$ sensor with an additional thick layer of $\mathrm{Ta}_{2} \mathrm{O}_{5}$ of about $150 \mathrm{~nm}$ as a barrier to prevent gold from migrating into the silicon. The starting layer of the actuator was a $0.5-\mu \mathrm{m}$ layer of gold deposited on the ISFET chip by thermal evaporation. After patterning by photolithography, an $\mathrm{SiO}_{2}$ layer of $c a .3 \mu \mathrm{m}$ was deposited by PECVD (plasma enhanced chemical vapour deposition) on the top of the gate as the sacrificial layer. Then a layer of gold thick-film paste (DuPont 9910) was deposited. After drying, the thick-film paste was sintered at $600^{\circ} \mathrm{C}$ in a nitrogen atmosphere. The etching of the sacrificial layer and the glass compound in the thick-film paste was carried out in buffered HF for $1.5 \mathrm{~h}$ with constant stirring. A typical thickness of the porous actuator obtained is $c a .100 \mu \mathrm{m}$. The chip was finally mounted on a printed circuit board and encapsulated by epoxy.

\section{Measurement set-up}

The buffer capacity measuring set-up is shown in Fig. 4. Since the current source is not floating, the grounded counter electrode also works as a reference electrode. In this case, the current at low frequency will cause a certain polarization in spite of the very large area of the counter electrode. This polarization potential of the counter electrode will be superposed on the output of the ISFET amplifier and will interfere with the measurement. Therefore, an additional saturated calomel electrode is used to measure the polarization potential separately, and the signal is sent to the lock-in amplifier for subtraction. The measured current and voltage are presented in effective (root mean square or RMS) values.

\section{Measurement protocol}

Before the proteins are dissolved the sample solution is bubbled with nitrogen for $15 \mathrm{~min}$. Then the protein is added and the solution is stirred for several minutes until it has completely dissolved. The measurement vessel was purged with nitrogen throughout the measurement. Potassium nitrate, $0.1 \mathrm{M}$, was used, as the supporting electrolyte. The $\mathrm{pH}$ was changed by adding $1.0 \mathrm{M}$ nitric acid or $1.0 \mathrm{M}$ potassium hydroxide to the

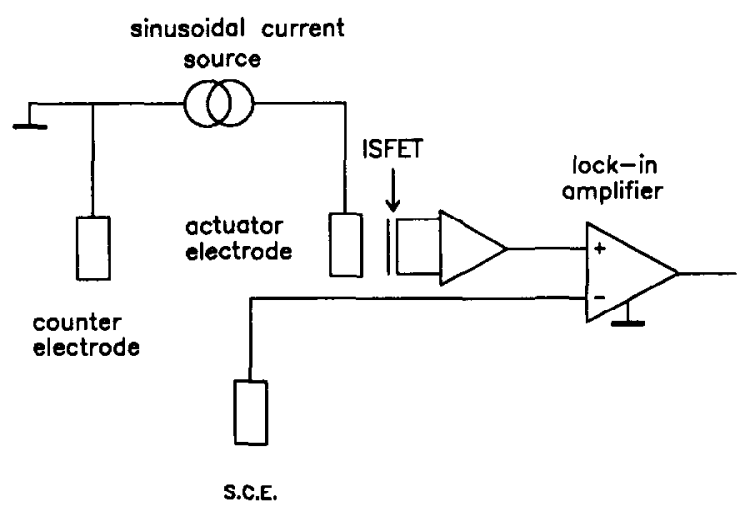

Fig. 4. Set-up for the buffer capacity measurement. 
sample solution, and was monitored by a $\mathrm{pH}$ meter with a glass electrode (radiometer). For all measurements the $\mathrm{pH}$ was changed from a high to a low value. A measurement for correction of the results for the buffer capacity of the blank solution without proteins was carried out in the supporting electrolyte.

\section{RESULTS AND DISCUSSION}

\section{Testing the system with acetic acid}

The buffering property of acetic acid at different $\mathrm{pH}$ values was measured and the results are shown in Fig. 5 (triangles joined by a solid line in the upper part of the figure). The measurement results are presented as the reciprocal of the ISFET amplifier output voltage $V_{\mathrm{s}}$. This reciprocal value of the measured results directly reflects the buffer capacity as a function of $\mathrm{pH}$. For comparison, the theoretical curve according to eqn. (13) was calculated, and is also shown in Fig. 5 (the lower part of the figure). At $\mathrm{pH}=$ $\mathrm{pKa}$, a maximum buffer capacity is expected. The measured results are in fairly good agreement with the theoretical description.

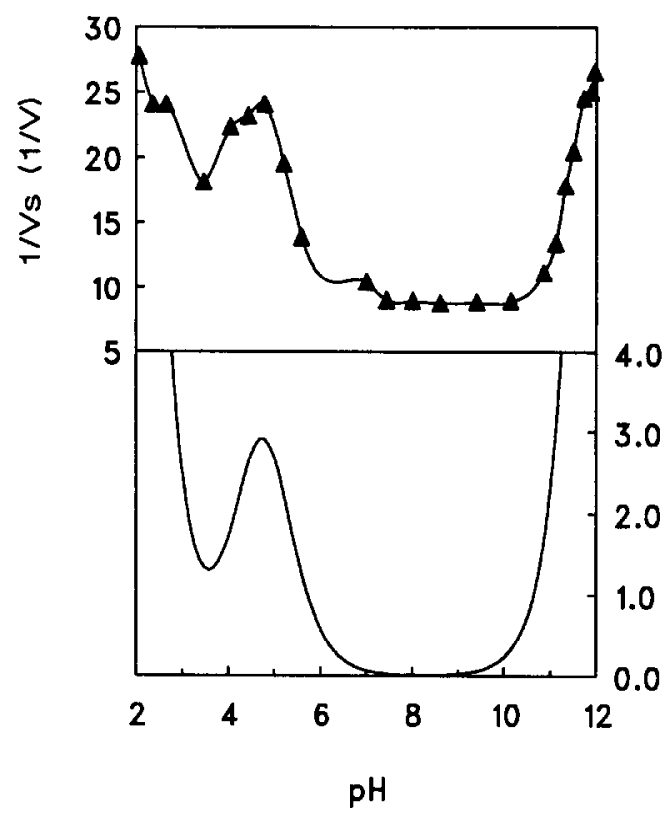

Fig. 5. Buffer capacity of $5 \mathrm{mM}$ acetic acid as a function of $\mathrm{pH} .\left[\mathrm{KNO}_{3}\right]=0.1 \mathrm{M}, \mathrm{I}=10 \mu \mathrm{A}, \mathrm{f}=1 \mathrm{~Hz}$. Upper marks and fitting line are from the measurements; lower curve is calculated.

\section{The buffer capacity of lysozyme and} ribonuclease

The buffer capacity measurements of lysozyme (Sigma L-2879) in two concentrations are presented in Fig. 6. The output voltage of the ISFET amplifier is again presented reciprocally, which corresponds to the measured buffer capacity. Figure 6 shows that the buffer capacity of lysozyme is a function of the $\mathrm{pH}$ as well as of the concentration of the protein solution. With increasing concentration of the protein solution, the measured buffer capacity curve shifts vertically along the $y$-axis. For the two concentrations measured, the lowest buffer capacity lies between $\mathrm{pH} 9$ and $\mathrm{pH} 10$. It appears that this lowest point is around the isoelectric point of lysozyme, which is reported to be about pH 11 (Tanford \& Wagner, 1954). The highest buffer capacity is found at about $\mathrm{pH} 4$.

Another protein, ribonuclease (Sigma R-4875), has also been investigated by buffer capacity measurements. The results are presented as a function of $\mathrm{pH}$ in Fig. 7. The concentration of ribonuclease is $5 \mathrm{~g} / \mathrm{l}$. The buffer capacity curve of ribonuclease differs from that of lysozyme. The lowest peak appears at about $\mathrm{pH} \mathrm{8}$, while two maxima appear at about $\mathrm{pH} \mathrm{4-5}$ and at $\mathrm{pH}$ 10-11. Besides the buffering difference at different $\mathrm{pH}$ values, the buffer capacity of ribonuclease over the $\mathrm{pH}$ range of concern is also found to be smaller than that of lysozyme. Considering the fact that the molecular weight of lysozyme

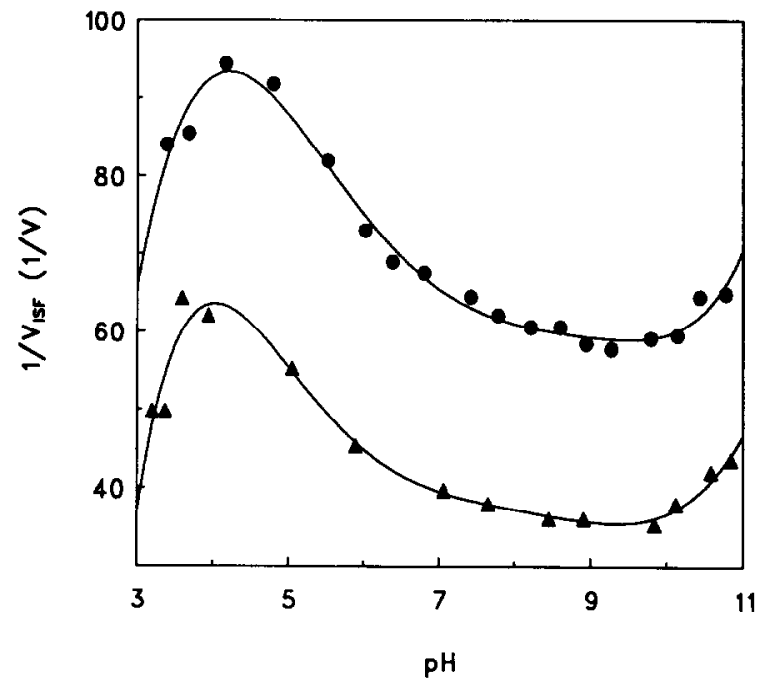

Fig. 6. Buffer capacity measurement of lysozyme in $0.1 \mathrm{M} \mathrm{KNO}_{3}$ without correction. $\Delta, 2 \mathrm{~g} / \mathrm{l}$, O, $5 \mathrm{~g} / \mathrm{l}$. 


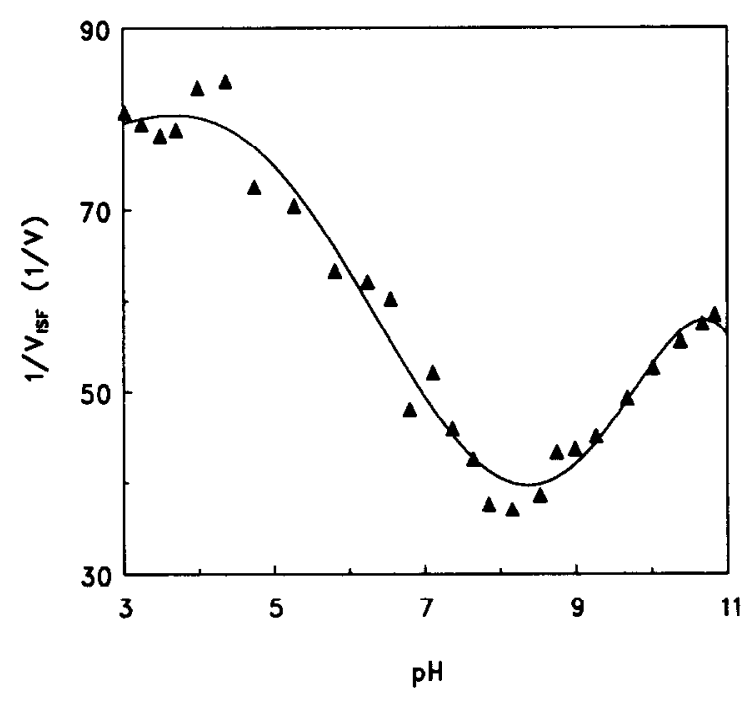

Fig. 7. Buffer capacity measurement of $5 \mathrm{~g} / \mathrm{l}$ ribonuclease in $0.1 \mathrm{M} \mathrm{KNO}_{3}$ without correction.

is slightly higher than that of ribonuclease, the mole concentration of ribonuclease is slightly higher in our experiment. This suggests that ribonuclease has fewer binding sites for protons, or that the static interaction that rejects further binding between the groups is stronger than in the case of lysozyme.

The difference between the buffer capacities of the two proteins is more distinct if a simple correction of the data with the measurement results of a blank solution is carried out. The corrected results of Figs. 6 and 7 for a protein concentration of $5 \mathrm{~g} / 1$ are presented in Fig. 8 .

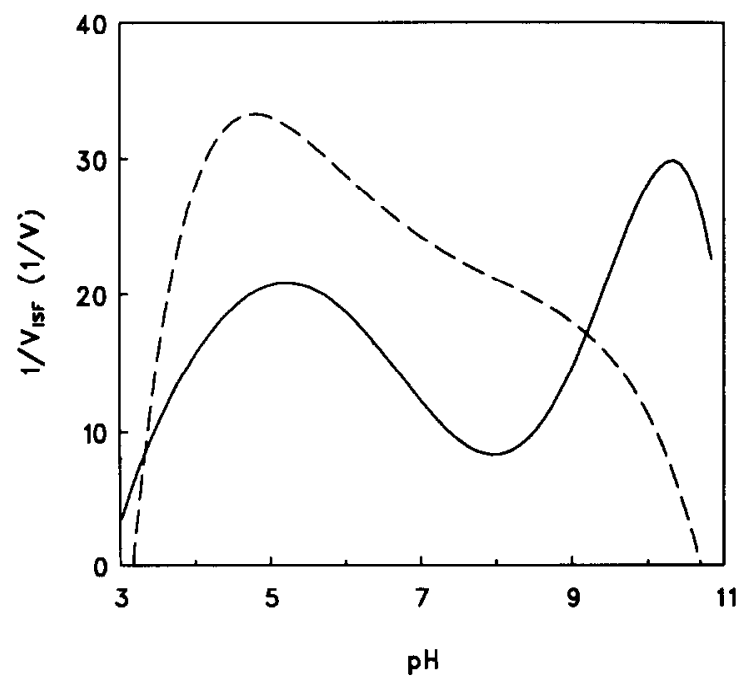

Fig. 8. Buffer capacity measurement of $5 \mathrm{~g} / \mathrm{l}$ ribonuclease (solid line) and lysozyme (broken line) after correction in $0.1 \mathrm{M} \mathrm{KNO}_{3}$.
After correction, the peaks in the curves are more evident. Lysozyme shows a high buffer capacity in the acidic region around $\mathrm{pH} 5$ and has almost no buffer function above $\mathrm{pH} 10$. Ribonuclease has a good buffer function in the acidic region around pH 5 as well as in the basic region around $\mathrm{pH} 10$, but shows a low buffer capacity in the neutral solution around $\mathrm{pH} 8$.

Finally, some remarks about the experimental results are necessary. The measured buffer capacity at a $\mathrm{pH}$ value higher than 11 or lower than 3 has a relatively large error, because at these extremes the protons or the hydroxyl ions will manifest themselves as a strong buffer. Furthermore, interpretation of the experimental results has not taken into account the kinetic effect, which might also be of importance in the case of the dynamic operation of the system. Therefore, the results obtained here are not exactly comparable to those carried out by a normal potentiometric titration. (Tanford, 1961)

\section{CONCLUDING REMARKS}

Specific affinity reactions of proteins can form the basis of biochemical sensors. One of the properties of a protein that can change during such a reaction is the buffer capacity. Buffer capacity can be measured with an ISFET-based sensor-actuator device. A model is presented, which describes the overall transfer from the electrical input at the actuator via the chemical domain, with the buffer capacity as a parameter, and vice versa to the electrical output of the ISFET $\mathrm{pH}$ sensor. The first measurement results show that the buffer capacity can be determined as expected, and that a clear difference is found in the buffering properties of, e.g., lysozyme and ribonuclease.

If the selective binding of a substance to a protein significantly changes the proton binding, which accounts for the buffer capacity of the protein, the detection of this change in buffer capacity allows the construction of a new type of biosensor.

\section{REFERENCES}

Abresch, K. \& Claassen, I. (1961). Coulometric Analysis. Chapman and Hall, London. p. 176. Ashworth, M.R.F. (1964). Titrimetric Organic Analy- 
sis. Part 1: Direct Methods. Interscience, New York.

Haschemeyer, R.H. \& Haschemeyer, A.E.V. (1973). Proteins. A Guide to Study by Physical and Chemical Methods. John Wiley, New York. pp. 254-295.

Lehninger, A.L. (1975). Biochemistry. Worth, New York, p. 79.

Luo, J., Olthuis, W., Bergveld, P., Bos, M. \& v.d. Linden, W.E. (1991). A porous gold actuator for the ISFET-based coulometric sensors-actuator systems, Transducers '91, Proceedings 6th International Conference on Solid-state Sensors and Actuators, San Francisco, September, pp. 229-232.

Luo, J., Olthuis, W., Bergveld, P., Bos, M. \& v.d. Linden, W.E. (1993). Modelling of coulometric sensors-actuator systems based on an ISFET with a porous actuator covering the gate. Anal. Chim. Acta, 274, 7-23.

Nagasawa, M. \& Holtzer, A. (1971). Dissociation equilibrium and potentiometric titration of $\beta$ lactoglobulin in acidic solutions. J. Am. Chem. Soc., 93, 606-611.

Nozaki, Y. \& Tanford, C. (1967). Protein as random coils. II. Hydrogen ion titration of ribonuclease in $6 \mathrm{M}$ guanidine hydrochloride. J. Am. Chem. Soc., 89, 742-735.

Olthuis, W., v.d. Schoot, B.H., Chavez F., \& Bergveld, P. (1989). A dipstick sensor for coulometric acid-base titration. Sensors \& Actuators, 17, 279-283.

Olthuis, W., Luo, J., v.d. Schoot, B.H., Bergveld, P., Bos, M. \& v.d. Linden, W.E. (1990). Modelling of non-steady-state concentration profiles at ISFET-based coulometric sensors-actuator systems. Anal. Chim. Acta., 229, 71-81.
Perrin, D.D. \& Dempsey, B. (1974). Buffers for $p H$ and Metal Ion Control. Chapman \& Hall, London, p. 11.

Roxby, R. \& Tanford, C. (1971). Hydrogen ion titration curve of lysozyme in $6 \mathrm{M}$ guanidine hydrochloride. Biochemistry, 10, 3348-3352.

Schasfoort, R.B.M., Kooyman, R.P.M., Bergveld P. \& Greve, J. (1990). A new approach to immunoFET operation. Biosensors \& Bioelectronics, 5, 103-124.

Steinhardt, J. \& Reynolds, J.A. (1969). Multiple Equilibria in Proteins. Molecular Biology Series. Academic Press, New York, London.

Tanford, C., Swanson S.A. \& Shore, W.S. (1955). Hydrogen ion equilibria of bovine serum albumin. J. Am. Chem. Soc., 77, 6414-6421.

Tanford, C., (1962). The interpretation of hydrogen ion titration curves of proteins. Adv. Protein Chem., 17, 70-165.

Tanford, C., (1961). The Physical Chemistry of Macromolecules. John Wiley, New York.

Tanford, C. \& Epstein, J. (1954a). The physical chemistry of insulin. II. Hydrogen ion titration curve of zinc-free insulin. J. Am. Chem. Soc., 76, 2163-2169.

Tanford, C. \& Epstein, J. (1954b). The physical chemistry of insulin. II. Hydrogen ion titration curve of crystalline zinc insulin. The nature of its combination with zinc. J. Am. Chem. Soc., 76, 2170-2176.

Tanford, C. \& Wagner, M. (1954). Hydrogen ion equilibria of lysozyme. J. Am. Chem. Soc., 76 3331-3336.

van der Schoot, B.H. \& Bergveld, P. (1988). ISFETbased enzyme sensors. Biosensors, 2, 161-186. 